\title{
Seeing the unseen: an Indigenous heritage's mapping project
}

\author{
Justine Gagnon ${ }^{\mathrm{a}}$ \\ ${ }^{a}$ Université Laval, Québec, Québec, Canada: Justine.gagnon.1@ulaval.ca
}

\begin{abstract}
Based on an ongoing qualitative and collaborative research project led in partnership with the Innu community of Pessamit, this paper brings into focus some specific issues regarding memories recollection and representation in a context of deterritorialization. The Innu First Nation has a specific historical and political context related to resources exploitation. Since their traditional lands have been the site of several large-scale hydroelectric projects, they have been intimately - and to a large extent, forcibly - involved in the economic transformation of Quebec since the 1950s. It should be noted, however, that their ancestral occupation has never been formerly recognized by the federal and provincial governments, a political and legal context partly responsible for the material and cultural losses they had to deal with. Through interviews we have conducted with the elders that travelled the rivers before the floods, we tried to rebuild, in some way, the cultural heritage embedded in those submerged lands. We used different cartographic tools and materials in a way to support and trigger the personal narratives the elders were remembering and sharing. This cultural mapping process revealed three main issues I would like to focus on. First, as the cartographic representations were getting closer to the landscapes the elders perceived and experimented as kids and young adults, the localization of significant places and the creation of personal narratives became easier and fluid. Secondly, we found, through that inquiry, how important an enhanced visibility of innu's flooded heritage can be on a political level. Finally, we came to the conclusion that mapping should be considered more as a conversation than a visual representation only.
\end{abstract}

Keywords: Indigenous geographies, memories mapping, hydroelectricity, Quebec industrial development, memoryframe, aerial pictures, flooded landscapes, decolonization, remembering process, places memory, deep mapping, symbolic accretion, cultural claim, land claim.

\section{Introduction}

Sitting around a table covered with different maps, Edgar, an elder from the Pessamit community and myself, are looking attentively to the Innu Nation's ancestral land, trying to imagine how it looked like before hydroelectricity facilities were built on the three main rivers Innu people used as canoeing highways to reach their hunting places, situated in the Northern parts of the territory.

"Are there any places of importance that have been flooded after the Manic-5 dam was built on the Manicouagan river in 1970?" I ask him.

"Hmmm... this is pretty hard to identify on this map" he says. "Actually we would need another map with a different scale. Even better, we should go directly on site and I will show you."

Pointing at the map, he continues: "Here, you see, there were many trees before, but then when the reservoir overflows, they open the valve and let the excess of water flow over the land. Because of that, there are no traces left from the portage we used to call Uamashtakan, a word that signify 'where you have to get around, to bypass.' Be- cause of the waterfall that was standing there, we couldn't go through in our canoes. We had to portage around it. But we went there a few years ago with a guy from the land and resources office and we found a small section of the old portage, around here, as well as the remains of an old grave. For someone who knew this place before, it is still possible to imagine where it was approximately..."

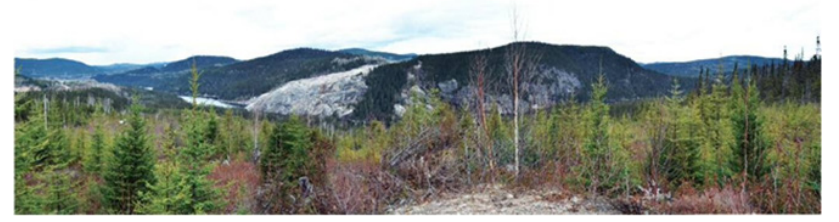

Figure 1: Here is a panoramic view, taken from the opposite side of the river, of the hill that the old portage would cross over. We can also see, on the left part of the picture, the area where flow the excess of water

(Personal collection, 2016). 


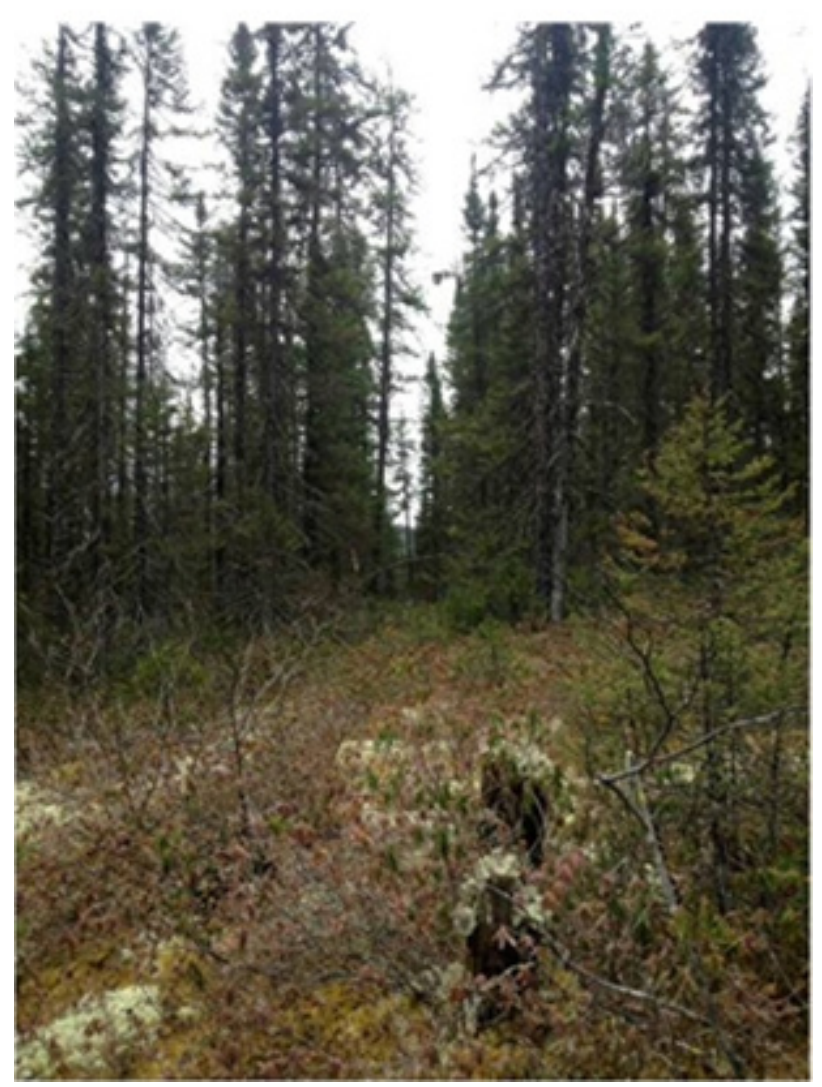

Figure 2: Here is the trace of the old portage.

We can quite easily perceive the path, even if it hasn't been used for more than sixty years (Personal collection, 2016).

“And why is this place significant to you?" I ask.

"Actually, it is one of the longest portages on the Manicouagan River. Innu people used to walk around 8 or $9 \mathrm{~km}$ to bypass the big waterfall. When we were carrying our stuff, we had to walk about $1,5 \mathrm{~km}$, after that we would go back to get other stuff and so on. One time we took one week to go through it with my family. That's probably why people used to say that it was one of the longest portages. But everyone always got through and we never had any problems. There was always mutual assistance between families. When you were done with your own material, you would go help the others to bring theirs."

While I listen to Edgar's story, I look to this little spot on the map, but the only thing I can see is the Manic-5 dam and the huge reservoir it has created. Personally, I am so used to see this topography that I can barely imagine the past landscapes Edgar is talking about. Moreover, I am part of the society that built the dam and claimed this land to be theirs at the time. This was supposed to be one of the Québécois's biggest achievements in the 1960s, a brilliant technological feat able to transform Quebec into a modern state.
"Did people lose some camps or equipment because of the flooding?" I ask Edgar.

"My family's traditional land is just there, directly in the middle of the actual reservoir. I was born there in 1935 and we had about 4 camps. In total, on this part of the land, there were maybe 10 camps and on a larger scale, I would say a hundred, like a small village. There were also graves, but most of them were repatriated before the flood. But we lost our traps, our tents... We had some traplines and people would leave their traps all year long so, obviously, they now lie underwater."

According to Edgar, when the dam was built on the Manicouagan River, the area that is now the reservoir filled with water pretty fast because the old river was very narrow in some places. When he went back after the flooding, he couldn't recognize his own land. Clearly, the discussion we are having has a deep emotional resonance. His family has never been able to go back to these lands after the dam was built.

Edgar's story is unfortunately not a unique one; many Innus coming from the nine communities located in Quebec share similar losses because of development projects that they have been removed from. Since their traditional lands have been the site of several large-scale hydroelectric projets (Charest, 2008), the Innus have been intimately - and to a large extent, forcibly - involved in the economic transformation of Quebec since the 1950s. It should be noted, however, that their ancestral occupation has never been formerly recognized by the federal and provincial governments. When the ManicBersimis-Outarde complex was built, some families got a small compensation (around $100 \$$ per familly), an insignificant amount compared to the equipment, hunting territories, and economic activities and resources they lost access to. But if these transformations led to the destruction of many significant cultural landscapes, they never fully extinguished the representations and the memory Innu people have of these cherished places.

That said, my exchanges with the people of Pessamit have led me to question, among other things, how can place attachment survive when these places are gone or when they are not accessible anymore? How does memory work to recall or rebuild localized events or emotions, while the remembering subject cannot stand inplace anymore? But more accurately, what role may a culturally adapted mapping activity play in such a remembering and commemorating process?

In the following sections, recounting the different methodological steps my partners and I went through, we will thus see to what extent maps - and mapping - may (1) awake and produce memories, (2) offer a counternarrative to the dominant voices that have themselves heard in some landscapes and (3) add a new set of "words" that the inter- generational and intercultural dialog the Pessamit community is engaged in could be based on. 


\section{Maps as memory-frames}

Edgar and I met a few times to talk about his family's land and the Manicouagan River more broadly. I asked him questions about the canoeing journeys his family and himself made every fall to reach their campsites, the hunting activities they used to practice during the winter and more especially, about the impacts the hydroelectricity facilities have had on their way of life, as well as on the places they used to inhabit. Each time we met, I brought different geographical material to rely on and he brought his own maps too, so that he could show me what places he was talking about. We first looked at classical topographic maps, plus a map where the Innu place names were indicated, as well as some of the old portages (Figures 3, 4 and 5). In spite of their large scale and basic design, the reading of these maps opened some interesting avenues of inquiry. The map on which Innu place names were identified along the rivers yielded some important input and helped Edgar to order the mental landscapes and paths he was trying to explain and restore. Even though they could not quite render the texture of what the land is made of, these maps constituted a good starting point. After locating some key places thanks to their Innu names and the topographic particularities these designations are based on, Edgar - as well as the other persons we interviewed - found some of his bearings through the cartographic representation.

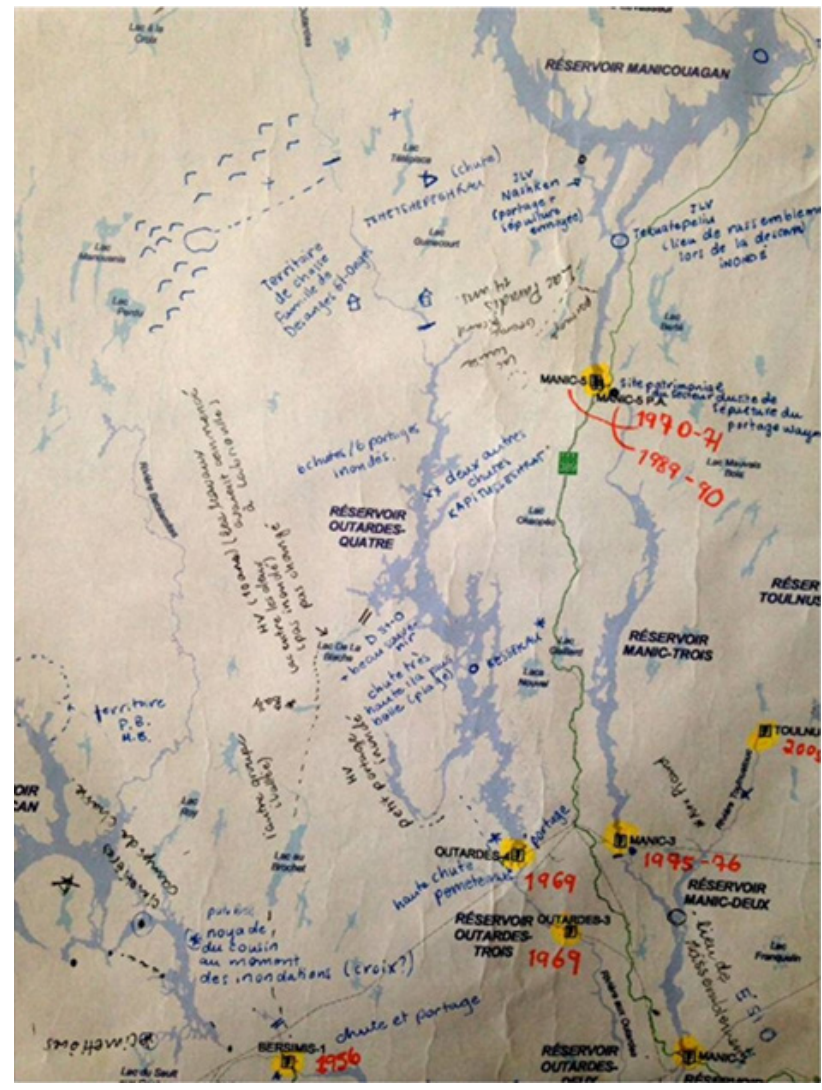

Figure 3: Picture of a topographic map that we used during the interviews (2015)
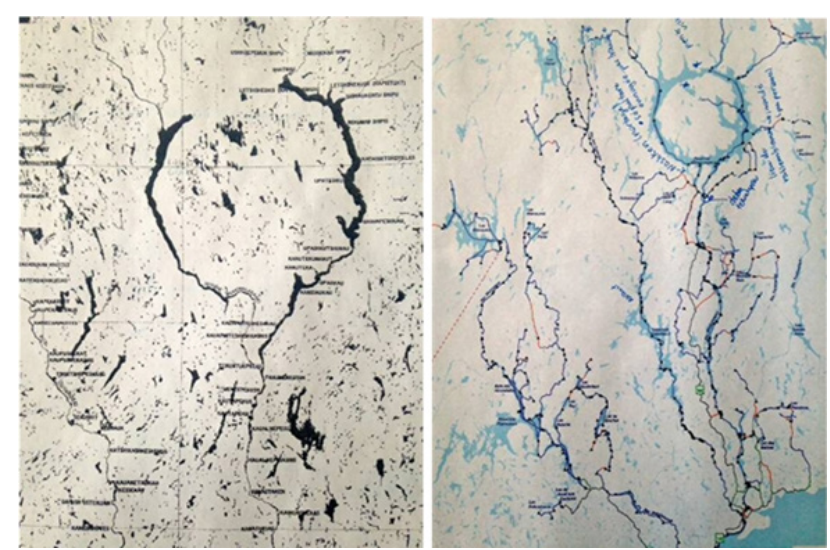

Figures 4 and 5: Pictures of the topographic maps we used during the interviews; one including Innu toponyms

(4) and the other the routes and portages (5) (2015)

Nevertheless, the identification of some specific places was constrained by the maps' imprecision. At the same time, since I was not familiar with those lands, it was difficult to understand and imagine the landscapes Edgar's stories were embedded in without a better visual support. So we decided to look at Google Earth to have a better idea of the topography Edgar was recalling (figure 6). Still, because of the flooding, our inquiry was made more difficult due to the masses of water covering most of the land and making some of Edgar's bearings pretty hard to find. We were also limited, in some way, by the Western cartographic convention, which structures most of the contemporary maps that are broadly available, and from which we can only gain a sense of the Manicouagan River - and any other landscape for that matter - as a fixed location in space, a uniform and homogenous surface devoid of human experience (Pearce, 2008).

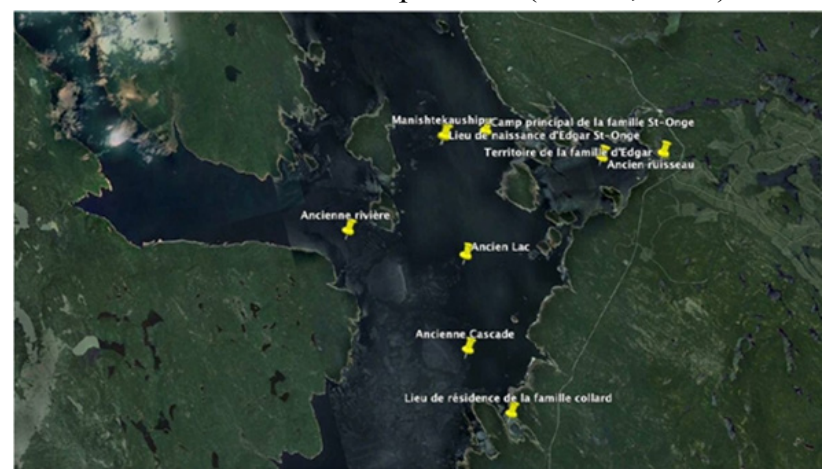

Figure 6: Screen shot of a Google Earth map on which some of Edgar's reference points have been inscribed.

As we can see, most of them are covered by water (2015). We ended up working with national aerial pictures taken between 1940 and 1960 approximately, which we first georeferenced with an ArcGIS program, and then opened in Google earth to make them easy to manipulate during interviews (figures 7, 8 and 9). By using images taken before the flooding and by shifting the viewing angle to one situated in place as much as we could (Pearce, 2008), the representation we were looking at started to get closer to the landscapes Edgar perceived and experimented as a child; as a result, the localisation of significant places and 
the creation of personal narratives became easier and more fluid. His knowledge of the region and, with it, his ability to situate himself within the historical context of journeys previously made (Ingold, 2000), were enhanced by the relationship he could then establish with his land and the emotional charge it contains. The mere points we started with became mountains, streams or lakes, and then "the place where he was born", "the place his family used to camp be- fore getting into a portage" or "the place where one was buried." In return, the retelling of journeys, events and experiences, led to remembering the steps, paths and places they were connected to, a process that is, in the end, pretty close to "mapping" (Ingold, 2000). For Ingold, since travelling from one place to another means remembering the way, all wayfinding becomes similar to mapping.

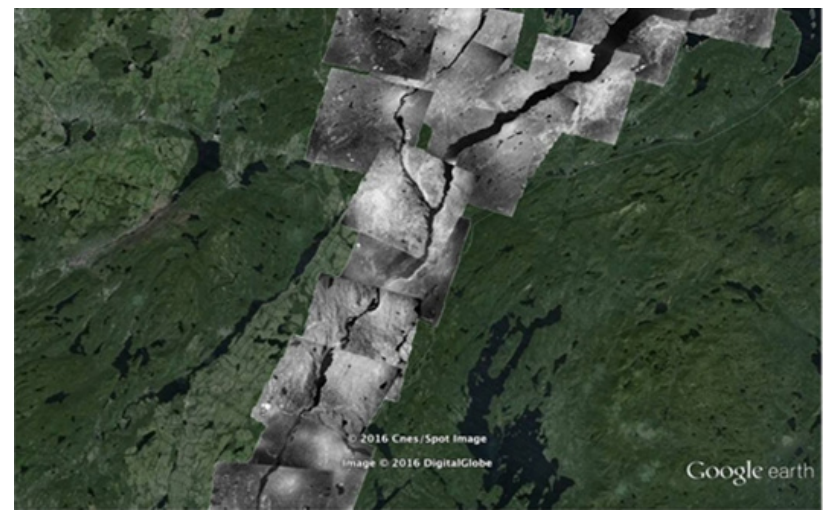

Figure 7: Aerial pictures taken between 1940 and 1960, which we first georeferenced with an ArcGIS program,

and then opened in Google earth (2016)

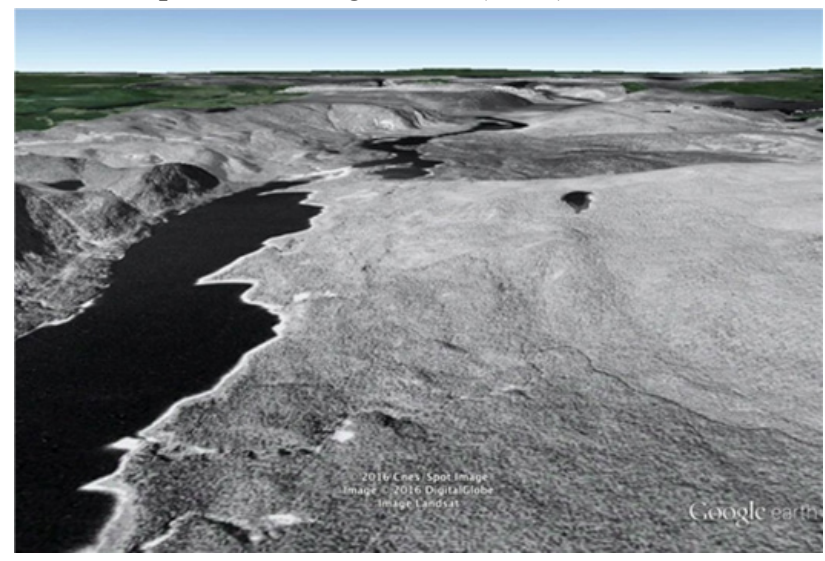

Figure 8: Same as Figure 5 with a different angle, so that we get closer to the real landscape (2016)

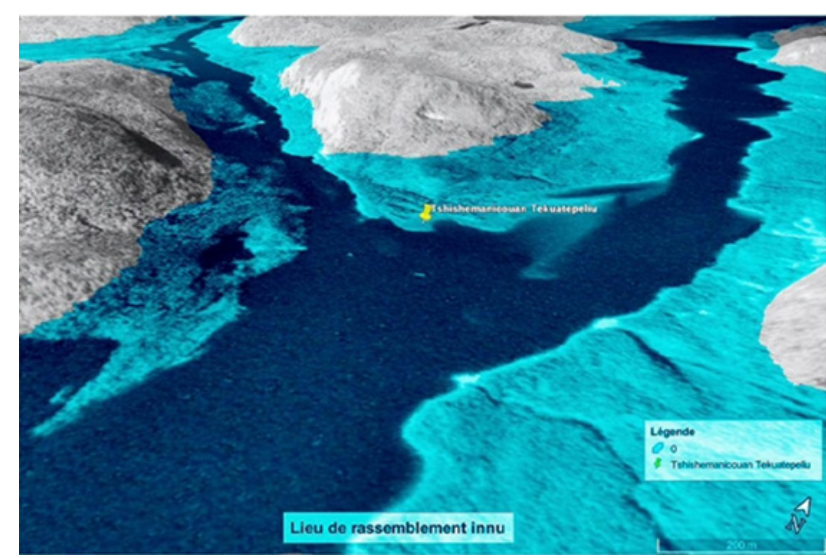

Figure 9: Photomontage using old aerial picture opened in Google Earth to show before and after the flood (2016)

Through his phenomenological approach of memory and remembering, Edward Casey brings interesting analytical keys to understand how it is possible to remember events and feelings that are necessarily geographically situated, even though the environment they are linked to has radically changed, or even disappeared. Like Ingold, Casey supports the idea that memory always results from a constant interaction between the "reminiscer" and the world he/she lives in. The body, he writes, is shaped by the places it has come to know and that have come to it by a special kind of "placial" incorporation that is crucial to the human self (Casey, 2000). This impressionism of place by which the presence of a place remains lodged in our body long after we have left that place, may be revived when the appropriate sensation arises, and thus serve as a "memory-frame" by which the experience or event remembered may be situated. This memory-frame acts as an underlying field of presentation for the specific content of memory and, in some way, ensures its permanence. While the building of memories calls upon the environment they are linked to, the latter contains and acts as a catalyst for the memories called forth; a perspective that echoes Donohoe's ideas when she suggests that: "[M]any places are embodied in such a way that we carry them with us and they in- form our constitution of the world. We do not engage in deliberate attempts to remember such places, but they in- habit our memories in the way in which we move through the world" (2014: 3).

But the awakening of embodied knowledge, which is related to the environment one is moving through, usually implies a physical presence. We then come back to my initial query. If the impressionism of a place can be revived, as Casey says, through the sensation raised by a particular landscape, could a representation of that place also trigger a similar process? In other words, can geographical representations, as maps for instance, elicit an emotional and affective response (Griffin and McQuoid, 2012) so that a memory-frame is created and can be used to stimulate the remembering process? Following Casey, I propose that coming to know a place implies the ordering of items to be remembered onto a virtual grid. While the remembering of these items occurs by revisiting the place-grid, conversely the remembering 
of place-grid occurs by revisiting the items (Casey, 2000). This would mean that a geo- graphical representation that gets as close as possible to the "placegrid" mentioned above may be able to support and stimulate the building of memories. As Casey explains, " even if it lacks the massive solidity and the unendingness that we find in the perceived world, the world of the remembered does exhibit consistency and persistence as part of a given memory-frame " (2000: 69). We could thus say that as he was looking to a landscape he crossed step by step many years ago, Edgar was revisiting, in a certain way, a "place-grid" onto which were "ordered" the experiences he once lived and the emotions associated with them (Casey, 2000).

Indeed, without the possibility to "be" in such places because of their disappearance or inaccessibility, the visuality offered by some pictures - the old aerial pictures in this case - successfully acted as a memory-frame, underlying stories and sustaining the items remembered. At the same time, Edgar's stories gave a sense and a structure to the landscapes he was looking at. As Ingold would say, "to tell is not to represent the world but to trace a path through it that others can follow" (2011: 162). Indeed, narratives help us to organize the spaces and places in which we find ourselves or which we can look at thanks to representations (Donohoe, 2014). Due to the way the spirit of place (genius loci) gets embedded into our body while we stand there and move around, we might only need a map, a painting or a photograph to trigger the remembering process that will make visible again what has become so thoroughly embodied, namely an emotional geography (Casey, 1983).

Moreover, the different perspectives and the apparent "realism" aerial pictures offer may constitute a better support to incorporate the stories, affect and experiences Pessamiulnut ${ }^{1}$ elders want to share, transmit and make more visible to younger generations. Even if, of course, the scale is not the same, these images resemble more closely the landscapes elders experienced during past journeys. Taking advantage of these pictures in collaborative cartography, with the aim of mapping immaterial and relational elements, can thus lead to the gradual incorporation of Indigenous voices, experiences, and worldviews (Warf, 2015) within national cultural landscapes like the hydroelectric ones.

\section{Maps as symbolic accretion}

In addition to their "triggering" role, maps can also serve as "archives", in storing up cultural features and, to a certain point, make them more visible to a targeted group. Actually, the identification of significant cultural places as portages, graves, camps or gathering sites, and with it the retelling of stories that express their special meaning and vocation, is part of a larger political effort to assert the Pessamiulnut's cultural presence in the hydroelectric landscape, as well as on the North Shore more generally.

1 The word "Pessamiulnut" designates the people of

Pessamit community in Innu language.
Since they never ceded their lands during the colonization period, the Innu Nations of Quebec are presently claiming formal recognition of their rights to territory and selfdetermination, a legal process that requires what the Canadian law calls a "proof of continuous land occupation". In that specific context, the reenactment of cultural landscapes that have been invisibilized, through the cultural map- ping process for instance, may play a crucial role. In fact, even though this occupation has been rendered invisible through colonial, technological gazing, such a heritage enhancement adds another layer of information for decoding the landscape of hydro power. Otherwise, the cultural transmission of landscape memories from elders to the younger generation - and the interfacing of these memories with the youth's own cultural landscapes - in itself is proof of continuity.

The mapping process the Pessamit community is going through, in putting invisibilized landscapes to the fore, thus appends an alternative, even antagonistic narrative to the national memory embodied by hydroelectric landscapes, which stand as geosymbols of Quebec's land appropriation through the spreading of extractive industries in the province's Northern regions (Desbiens, 2013). Actually, any cultural landscape, in a manner analogous to the geologic process of sedimentation, uplift, and erosion, undergoes symbolic accretion over time as different historical meanings are layered onto them, thus challenging the notion that these symbols have a final, established meaning (Dwyer \& Alderman, 2008). Places, says Ingold, enfold the passage of time: they are neither of the past, present or future but all three rolled into one. Endlessly generated through the comings and goings of their inhabitants, he adds, they figure not as locations in space but as specific vortices in a current of movement, of innumerable journeys actually made (Ingold, 2000: 238). The world is filled with perceptual objects, historical events, signs, texts, and rituals that mutually interact and, in doing so, change one another (Casey, 2000: 288). But obviously, some events, signs or rituals tend to dominate the others, dictating what historical meaning one landscape will incarnate and whose symbols will be visible. That being so, the hidden symbols may be harder to disclose; it doesn't mean, however, that they aren't significant anymore for those to whom they act as cultural bearings. In that context, localizing Innu's cultural heritage through storytelling and community mapping may constitute a step in the right direction.

In that sense, symbolic accretion is not only a way of analyzing the stratigraphy of ideologies conveyed on and through landscapes - as well as through any geographical representation -; it also represents a political strategy used by minority groups to expose their commemorative vision via an established memorial presence, or a map that otherwise would show only a single part of reality. Such a counter-narrative may enhance minorities' visible presence and protect their cultural sovereignty (Dwyer \& Alderman, 2008). So the mapping activities we are working on with the Pessamit community may certainly serve as a commemorative vehicle that allows the 
remembered events or stories to be regained in collective memory, but also to be highlighted in a way that increases their visibility onto these profoundly altered landscapes. Our process so far has also revealed a subtle distinction between existence and presence. As we have shown, even if some of the places and landscapes the Pessamiulnut are intimately attached to have been destroyed, they nonetheless remain present through their personal and collective memories. Along the Manicouagan river, countless birth places, graves, family camps, portages or seasonal gathering sites have been rendered invisible physically but not symbolically.

\section{Maps as language and conversation}

This means that in spite of the extensive transformations innu cultural landscapes have been subjected to, the dialog between Pessamit inhabitants and their land continues, and it does so thanks to the way they mobilize the per- formative, process-oriented potential of community cartography as conversation. As a Québécois researcher, both cultural and economic heirs of the hydroelectric colonization of Innu rivers, I feel privileged to have been invited to this conversation as it gives me the tools to see these landscapes again as part of a historical narrative, not of rupture and disappearance, but of continuity.

As my project made clear, the use of such flexible, evolving, multi-layered maps may ultimately serve as a medium that can support and stimulate an intergenerational and intercultural dialog. During interviews with the elders, our research partners (who were also the translators) were obviously learning a lot about their own land and the way their ancestors used to journey across it. Since most of the dams were built during the $50 \mathrm{~s}$ and $60 \mathrm{~s}$, the younger generations are not familiar with the previous landscapes. Although they are very knowledgeable of its actual topography, the old aerial pictures added a set of new words to the geographical language they are used to. They also had access, in this way, to an emotional background they were not necessarily aware of, thus sharing with the storytellers something like a broader sense of place, embedded in a specific historical context. As Davidson and Milligan argue, "emotions, then, might be seen as a form of connective tissue that links experiential geographies of the human psyche and physic with broader social geographies of place" (2004: 524). For our part, the process we were going through - which could be referred to as "deep mapping" (Bodenhamer and al., 2015; Roberts, 2016) adding emotional significance to the visually restored landscapes - helped us to better understand the social and cultural complexity of travelling in canoes on such distances, as well as living most of the year in these "remote" areas. Without such a detailed perspective of the small island in the middle of the river or the fork where a smaller river meets the main stream, we would have barely understood what a "meeting point", a "grave", a "portage" or a "family camp- site" really mean for the Pessamiulnut. Besides their primary role as memory-frames, these maps and visual representations also served as a language and a conversation.

\section{Conclusion}

The re-enactment of Innu lived geographies in the midst of hydrocolonialism's most powerful tool of erasure - the reservoir - has allowed us to outline these marks that show through and, in doing so, shift the narrative of memory and belonging in Quebec. Through an interconnection between the cartographic materials we had access to (Innu toponyms and portages maps, Google earth, georeferenced old aerial pictures, etc.) and the elders memories, we thus developed a mapping process that could simultaneously trigger the remembering activity, enhance Innus' visibility on their own land even on the virtual level offered by maps - and finally, support the intergenerational and intercultural dialog.

\section{Acknowledgements}

I am grateful to the Pessamit community members, and more especially to my research collaborators Éric Canapé, Sébastien Picard, An- dré Côté and Adélard Benjamin. My work is funded under the grant [752-20131575, 890-2014-0038] from the Social Sciences and $\mathrm{Hu}-$ manities Research Council of Canada.

\section{References}

BODENHAMER, David J., CORRIGAN, John, HARRIS, Trevor M. 2015. Deep maps and spatial narratives. Indiana : Indiana Uni- versity Press, 242p.

CASEY, Edward S. 2000. Remembering : A phenomenological study. Second Edition. Indiana : Indiana University Press, 362p.

----. 1983. « Keeping the past in mind », The Review of Metaphysics, 37 : 1, p. 77-95.

CHAREST, Paul. 2008. " More dams for Nitassinan: New Business Partnerships between Hydro-Québec and Innu communities

",, in MARTIN, Thibault et Steven M. HOFFMAN (dir.), Power struggle. Hydro development and First nations in Manitoba and Quebec, Winnipeg : University of Manitoba Press, p.225-279.

DAVIDSON, Joyce and MILLIGAN, Christine. 2004. « Embodying emotion sensing space : introducing emotional geographies », Social and Cultural Geography, $5:$, p.523-532.

DESBIENS, Caroline. 2013. Power from the North: The cultural geography of hydroelectricity in Quebec. Vancouver: UBC Press.

DONOHOE, Janet. 2014. Remembering places : A phenomenological Study of the Relationship between Memory and Place. Lexington Books : London, 155p.

DWYER, Owen, J. \& ALDERMAN, Derek, H. 2008. "Memorial landscapes: analytic questions and metaphors", Geojournal. 73, p. 165-178.

GRIFFIN, Amy et MCQUOID, Julia. 2012. "At the intersection of maps and emotion: The challenge of 
spatially representing ex- perience", Kartographische Nachrichten, 66: 6, p. 291-299.

INGOLD, Tim. 2000. The perception of the environment. Essays in livehood, dwelling and skill. London \& New York : Rou- tledge, 465p.

----. 2011. Being alive. Essays on movement, knowledge and description. London and New York: Routledge, 289p.

PEARCE, W. Margaret. 2008. « Framing the days : place and narrative in cartography ", Cartography and Geographic Information Science, 35, 1, p. 17-32.

ROBERTS, Les(ed.). 2016. «Deep Mapping. Humanities » [Online]:

http://www.mdpi.com/journal/humanities/special_issues /DeepMapping).

WARF, Barney. 2015. "Deep mapping and neogeography", in Bodenhamer, D. J. et al. Deep maps and spatial narratives. In- diana: Indiana University Press, 242p. 